\title{
First Brazilian consensus on the management of localized and locally advanced urothelial bladder cancer: a SBU-SBOC-SBRT-LACOG-GU panel review
}

Primeiro consenso brasileiro sobre o manejo do câncer de bexiga urotelial localizado e localmente avançado: uma revisão do painel SBU-SBOC-SBRT-LACOG-GU

Lucas Nogueira ${ }^{1,2}$, Icaro Thiago de Carvalho ${ }^{3,4}$, Ary Adamy Junior ${ }^{5}$, Daher Chade ${ }^{6}$. Luis Felipe Piovesan 7 , Ricardo Favaretto ${ }^{8}$, Allisson Bruno Barcelos Borges ${ }^{9}$, Arthur Accioly ${ }^{10,11}$, Diogo Assed Bastos $^{12,13}$, Diogo Augusto Rodrigues da Rosa ${ }^{14}$, Fernando C Maluf8,15,16, Andrey Soares ${ }^{15,17}$

\begin{abstract}
Introduction: Urothelial carcinoma, especially localized bladder cancer, has a substantial prevalence in Brazil with 9,480 new cases each year and 3,903 deaths, therefore progress is required in its management in order to decrease its recurrence and progression, and improve survival. Material and Methods: Medical oncologists, radiation oncologists, and urologists from Brazil conducted a meeting to vote the best approaches available in this country in the diagnosis, staging, and treatment of localized and locally advanced urothelial bladder carcinoma. The panel drew up 73 questions and answers were chosen considering the feasibility according to the access to drugs and the procedures used in this country. Each answer reaching $75 \%$ of voters was considered a consensus. The results of this consensus were compared with evidence published in the medical literature and rated with a level of evidence and grade of recommendation using the Oxford classification. Results: Transurethral resection of bladder tumors confirms the diagnosis of and provides initial treatment for non-muscle-invasive bladder cancers. Repeated resection is necessary in selected cases and should not delay
\end{abstract}

1. Universidade Federal de Minas Gerais, Urology Service, Surgery Department - Belo Horizonte - Minas Gerais - Brazil

2. Memorial Sloan Kettering Cancer Center, Urology - New York - NY - United States

3. Instituto Abathon, Radiation Oncology - Sao Paulo - Sao Paulo - Brazil

4. Hospital Israelita Albert Einstein, Radiation Oncology - Sao Paulo - Sao Paulo - Brazil

5. Hospital Santa Casa de Curitiba, Urology - Curitiba - Paraná - Brazil

6. Instituto do Câncer do Estado de São Paulo da Faculdade de Medicina da USP, Urologic Oncology - Sao Paulo - Sao Paulo - Brazil

7. CEPON - Centro de Pesquisas Oncológicas, Urology - Florianópolis - Santa Catarina - Brazil

8. Beneficência Portuguesa, Urology - Sao Paulo - Sao Paulo - Brazil

9. Hospital DF Star, Radiation Oncology - Brasilia - Distrito Federal - Brazil

10. Hospital Português da Bahia, Radiation Oncology - Salvador - Bahia - Brazil

11. Hospital São Rafael, Radiation Oncology - Salvador - Bahia - Brazil

12. Instituto do Câncer do Estado de São Paulo da Faculdade de Medicina da USP, Medical Oncology - Sao Paulo - Sao Paulo - Brazil

13. Hospital Sírio-Libanês, Medical Oncology - Sao Paulo - Sao Paulo - Brazil

14. Grupo Oncoclínicas, Medical Oncology - Rio de Janeiro - Rio de Janeiro - Brazil

15. Hospital Israelita Albert Einstein, Medical Oncology - Sao Paulo - Sao Paulo - Brazil

16. Hospital Santa Lúcia, Medical Oncology - Brasilia - Distrito Federal - Brazil

17.Centro Paulista de Oncologia, Medical Oncology - Sao Paulo - Sao Paulo - Brazil

Conflicts of interest: The authors declare no conflict of interest relevant to this manuscript.

Correspondence author: Lucas Nogueira, - Universidade Federal de Minas Gerais, Urology Service, Surgery Department - Belo Horizonte -

Minas Gerais - Brazil

E-mail: lucasnog@globo.com 
further treatment. The use of intravesical Bacillus Calmette-Guérin is performed according to risk stratification, showing a significant reduction in tumor recurrence and progression, and improved disease-specific survival in intermediate- and high-risk patients. Radical cystectomy should be considered for high-progression risk cases after Bacillus Calmette-Guérin treatment failure and for localized muscle-invasive bladder cancer. Conclusion: Management of urothelial carcinoma often requires a multidisciplinary team with surgical and clinical approaches, based on the expertise of professionals and evidence from the literature.

Keywords: Urinary bladder neoplasms; Cystectomy; Consensus; Carcinoma, Transitional cell; Administration, Intravesical.

\section{RESUMO}

Introdução: O carcinoma urotelial, principalmente o câncer localizado de bexiga, tem prevalência substancial no Brasil com 9.480 novos casos a cada ano e 3.903 óbitos, portanto, é necessário avançar no seu manejo para diminuir sua recorrência e progressão, e melhorar a sobrevida. Material e Métodos: Médicos oncologistas, oncologistas de radiação e urologistas do Brasil realizaram uma reunião para votar as melhores abordagens disponíveis no país no diagnóstico, estadiamento e tratamento do carcinoma de bexiga urotelial localizado e localmente avançado. O painel elaborou 73 perguntas e as respostas foram escolhidas considerando a viabilidade de acordo com o acesso aos medicamentos e os procedimentos utilizados no país. Cada resposta que atingiu $75 \%$ dos eleitores foi considerada um consenso. Os resultados desse consenso foram comparados com as evidências publicadas na literatura médica e avaliados com um nível de evidência e grau de recomendação usando a classificação de Oxford. Resultados: A ressecção transuretral de tumores de bexiga confirma o diagnóstico e fornece tratamento inicial para cânceres de bexiga não músculo-invasivo. A ressecção repetida é necessária em casos selecionados e não deve atrasar o posterior tratamento. O uso do Bacillus Calmette-Guérin intravesical é realizado de acordo com a estratificação de risco, mostrando redução significativa na recorrência e progressão tumoral e melhora na sobrevida específica da doença em pacientes de risco intermediário e alto. A cistectomia radical deve ser considerada para casos de alto risco de progressão após falha no tratamento com Bacillus Calmette-Guérin e para câncer de bexiga músculo-invasivo localizado. Conclusão: O manejo do carcinoma urotelial muitas vezes requer uma equipe multidisciplinar com abordagens cirúrgicas e clínicas, com base na experiência dos profissionais e evidências da literatura.

Descritores: Neoplasias da bexiga urinária; Cistectomia; Consenso; Carcinoma de célula transicional; Administração intravesical.

\section{INTRODUCTION}

Urothelial carcinoma (UC), formerly known as transitional cell carcinoma, comprises carcinomas of the urethra, bladder, ureters, and renal pelvis, and it is the most frequent bladder cancer worldwide. Urothelial bladder carcinoma (UBC) is a common malignancy and was the sixth most prevalent cancer worldwide in 2018, with 539,393 new cases and 199,992 deaths. ${ }^{1}$ In Brazil, 3,903 deaths occurred due to UBC in 2015 and 9,480 new cases are expected per year for the 2018-2019 biennium. ${ }^{2}$ It is more frequent in Caucasians and in men (3:1), but women present with a worse prognosis, and incidence increases with age. $^{3-5}$ Tobacco use is the main risk factor, increas- ing recurrence risk ${ }^{6}$ and decreasing disease-specific and overall survival (OS). ${ }^{7}$ Other important risk factors are contact with other carcinogens, especially through occupational exposure, such as working with dye, rubber, paints, and solvents, a family history of bladder cancer, use of cyclophosphamide and pioglitazone, pelvic radiation, long-term bladder catheterization, HPV infection and Schistosoma haematobium infection. ${ }^{3,8,9}$ UBC can be categorized into non-muscle-invasive bladder cancer (NMIBC), muscle-invasive bladder cancer (MIBC), or metastatic disease. The non-muscle-invasive category encompasses $\mathrm{Ta}$, $\mathrm{T} 1$ reaching the lamina propria but sparing the detrusor muscle and carcinoma in situ 
(CIS). It is usually multifocal and corresponds to approximately $75 \%$ of the diagnoses of UBC. ${ }^{3,10}$ Despite available treatments, the recurrence rate of NMIBC is high - approximately $50 \%$ risk in 5 years, ${ }^{10-12}$ with a notable risk of progression - up to $20 \%$ of cases progress to the muscle-invasive stage, ${ }^{12}$ demanding life-long disease monitoring. MIBC at first diagnosis comprises the minority of cases, and despite a more aggressive approach such as radical cystectomy, perioperative chemotherapy or tri-modal treatment (TMT), it presents a high mortality rate for patients with distant metastatic disease, with a 5-year OS of less than $10 \% .^{13}$

This paper aimed to provide a consensus on the management of urothelial carcinoma in Brazil, to facilitate decision-making and provide a straightforward reference for physicians for the best practice available in this country considering the feasibility according to the limited access to drugs and procedures, such as unavailability of mitomycin, Bacillus Calmette-Guérin (BCG), and blue light cystoscopy.

\section{MATERIAL AND METHODS}

Experts representing The Brazilian Society of Clinical Oncology (SBOC), the Latin American Cooperative Oncology Group-Genitourinary (LACOG-GU), the Brazilian Society of Urology (SBU) and the Brazilian Society of Radiotherapy (SBRT) prepared 73 questions related to localized and locally advanced urothelial carcinoma and held a meeting in Sao Paulo, Brazil, to establish recommendations in the management of the disease with a focused on bladder cancer. They were 19 medical oncologists, 4 radiation oncologists, and 18 urologists with expertise in the management of bladder cancer, who were chosen by the above-mentioned institutions. The questions were presented to all participants for voting using electronic input device, and a consensus was achieved if one answer was chosen by at least $75 \%$ of the voters. Questions not reaching the consensus were voted once more after a brief discussion, and in case of failure to achieve at least $75 \%$ of total voters again, the most voted answer was considered the recommendation. Each participant could had abstain from voting if judged to be not prepared/not experienced enough to choose an answer or if they had any conflict of interest with the specific question.

Each chosen answer was rated with a level of evidence (LE) and grade of recommendation (GR), according to the medical literature using the 2009 Oxford Center for Evidence-Based Medicine Levels of Medicine classification ${ }^{14}$ (Table 1).

\section{RESULTS}

\section{Diagnosis and staging in NMIBC}

The goal of cancer screening is to provide an early diagnosis with the aim of achieving higher odds for cure. Screening tests should be cost-effective and accurate with high sensitivity and specificity, causing minimum harm and providing the best benefit. There is no standard screening test for urothelial

Table 1. Levels of evidence - Oxford Centre for Evidence-based Medicine, 2009.

\begin{tabular}{|c|c|}
\hline Level & Type of evidence \\
\hline la & Systematic review with homogeneity of randomized control trials \\
\hline $1 b$ & Individual randomized control trial with a narrow confidence interval \\
\hline $1 c$ & All or none related outcome \\
\hline $2 a$ & Systematic review with homogeneity of cohort studies \\
\hline $2 b$ & $\begin{array}{l}\text { Individual cohort study (including low-quality randomized control trials, } \\
\text { e.g., }<80 \% \text { follow-up) }\end{array}$ \\
\hline 2c & "Outcomes" research; Ecological studies \\
\hline $3 a$ & Systematic review with homogeneity of case - control studies \\
\hline $3 b$ & Individual case - control study \\
\hline 4 & Case-series (and poor-quality cohort and case - control studies) \\
\hline 5 & $\begin{array}{l}\text { Expert opinion without explicit critical appraisal, or based on physiolo- } \\
\text { gy, bench research or "first principles" }\end{array}$ \\
\hline \multicolumn{2}{|c|}{ Grades of recommendation } \\
\hline A & Consistent level 1 studies \\
\hline B & Consistent level 2 or 3 studies or extrapolations from level 1 studies \\
\hline C & Level 4 studies or extrapolations from level 2 or 3 studies \\
\hline $\mathrm{D}$ & Level 5 evidence or troublingly inconsistent or inconclusive studies of any level \\
\hline
\end{tabular}


bladder carcinoma, and therefore, routine screening should not be performed (consensus, LE: 5 GR: D). Most bladder cancer (BCa) cases are symptomatic; asymptomatic random findings being very rare, with only $2 \%$ of the general incidence. ${ }^{15,16}$ Screening could be evaluated in selected high-risk patients; ${ }^{17}$ however, there is still not enough evidence for this to be recommended as daily practice.

In patients with a suspicion of $\mathrm{BCa}$, evaluation with white light cystoscopy (WLC) is indicated, since it is considered the gold standard approach for BCa diagnosis and monitoring, especially for papillary lesions. ${ }^{18}$ However, cystoscopy is an invasive, costly, and time- consuming procedure that causes discomfort and pain for the patient, ${ }^{19}$ since flexible cystoscopies are not widely available in Brazil due to prohibitive costs. Therefore, in cases of suspected bladder lesions already seen on previous imaging examination, cystoscopy might be omitted, being used as necessary in the minority of cases prior to transurethral resection (TUR) where lesions had already been seen on previous imaging examination (consensus, LE: 5 GR: D). WLC is the most commonly used technique, despite limitations such as being unable to identify flat lesions, CIS or small papilloma.

Technologies such as narrow-band imaging or fluorescent cystoscopy should be used, if available, during the endoscopic evaluation of lesions in most cases (recommendation, LE: 1a GR: A), as they can improve tumor detection, ${ }^{20-22}$ with a $90 \%$ detection rate for $\mathrm{CIS}^{23}$ and a higher sensitivity compared to WLC. ${ }^{20,24}$ A better visualization results in a more complete resection, reducing the residual tumor rate ${ }^{25}$ and recurrence ${ }^{20}$, and potentially improving recurrence-free survival (RFS). ${ }^{26}$ Positive cytology and negative standard cystoscopy are a good indication for these new, yet more expensive and expendable, technologies. The upper urinary tract (UUT) should also always be evaluated in cases of positive cytology and negative standard cystoscopy (consensus, LE: 5 GR: D). UUT carcinoma is less frequent than UBC and usually presents as asymptomatic hematuria. ${ }^{27}$ The investigation should be performed by computed tomography (CT) or magnetic resonance imaging (MRI) and ureteroscopy (consensus, LE: 4 GR: C) because normal ultrasonography cannot rule out a diagnosis. ${ }^{28,29}$ CT urography has higher sensitivity, specificity, and detection rate accuracy of UUT carcinomas than intravenous urography. ${ }^{30} \mathrm{MRI}$ also has substantial sensitivity, specificity, and detection rate accuracy, ${ }^{31}$ but is mostly preferred in patients for whom CT is contraindicated, including an allergy to iodinated contrast agents or renal insufficiency. ${ }^{32}$ In patients with bladder tumors demonstrated by cystoscopy, imaging (CT or MRI) before TUR should be indicated only in those patients with high-grade tumors or suspicion of muscle layer invasion (consensus, LE: 5 GR: D). ${ }^{9}$

CIS is a non-muscle-invasive, high-grade tumor with a high-risk of recurrence and progression, corresponding to $10 \%$ of NMIBC cases. ${ }^{33}$ In cases of sus- pected CIS, random cold-cup biopsies should be performed, sampling the trigone, bladder dome, right, left, anterior and posterior bladder wall (consensus, LE: 1b GR: A) because CIS is usually a flat, multifocal tumor that can be macroscopically indistinguishable from normal mucosa. ${ }^{34,35}$ Random biopsies in suspected patients have shown a diagnosis of CIS in up to $25 \%$ of the population. . $^{36,37}$

Non-urothelial bladder carcinoma corresponds to less than $5 \%$ of bladder cancer cases $^{38}$ and should be considered high-risk tumors (consensus, LE: 2b GR: $\mathrm{B})$. In general, non-urothelial BCa is associated with lower survival rates when compared to UC, with median survival ranging from 17 months to 179 months, depending on the histology, and 5-year survival rates from 31 to $58 \% .^{39}$

\section{Transurethral resection of the bladder}

Transurethral resection of bladder tumor (TURBT) is the standard procedure for treating and diagnosing NMIBC. It consists of removing all visible tumors, including the apparently normal mucosa of the border, and resection of the muscle layer at the base of the tumor. ${ }^{40}$ The quality of the TURBT results in a decrease in the tumor recurrence rate. ${ }^{41,42}$ The presence of the muscular layer in a TURBT specimen is of utmost importance for the diagnosis, staging, and management of the disease. The presence of muscle in the initial specimen is associated with lower recurrence rates compared to TURBT without muscle, ${ }^{43}$ and it should always be present in the TURBT specimen; otherwise, a second TURBT will be necessary ${ }^{44}$ (consensus, LE: 1b GR: A). Sampling of the prostatic urethra leads to the detection of the involvement of the prostate as a result of the bladder cancer ascending through the prostatic urethra and the prostatic ducts/acini, which is related to higher urethral recurrence ${ }^{45}$ and lower survival rate. ${ }^{46}$ This sampling should be performed in the presence of CIS, in cases of tumors affecting the bladder neck and trigone, in the presence of multiple tumors or following positive cytology ${ }^{47,48}$ (consensus, LE: 1b GR: A).

Advanced age is one of the most important risk factors for bladder cancer; thus, it is not unusual to have patients with concomitant prostate hyperplasia. TUR of the prostate can be performed simultaneously with bladder tumor resection in most cases (recommendation, LE: 2a GR: B), as it does not interfere in overall tumor recurrence or recurrence in the bladder neck/prostatic fossa. ${ }^{49,50}$

TURBT must be repeated in cases where complete resection of the lesion was not feasible in the initial procedure (consensus, LE: 2b GR: A) and when the detrusor muscle was not present in the initial TURBT specimen in order to perform correct staging and decrease the recurrence risk ${ }^{43,44}$ (consensus, LE: $1 \mathrm{~b}$ GR: A), except in cases of TaLG/G1 tumors and primary $\mathrm{CIS}$. Incomplete resection is one of the mechanisms of early tumor recurrence, ${ }^{10}$ usually detected in the first three months after the initial TURBT. ${ }^{12}$ Repeat- 
ing TURBT (re- TURBT) removes the persistent tumor, confirms staging, and improves prognosis. ${ }^{10}$

A second endoscopic resection (re-TURBT) is indicated in high-grade cases, (consensus, LE: 4 GR: C), as the rate of recurrence of the remaining tumor from the first TURBT is reported to be up to $75 \%,{ }^{51}$ in cases of invasion of the lamina propria (consensus, LE: $1 \mathrm{~b} G R: A)$, reducing the recurrence rate and progression, ${ }^{52}$ and in cases with lymphovascular invasion in the specimen from the first surgery (consensus, LE: $2 \mathrm{~b}$ GR: B), because these findings are related to a worse prognosis, with a high recurrence rate and low RFS. ${ }^{33,54}$ Moreover, re-TURBT must not be delayed; it should be performed 1 to 6 weeks after the initial TURBT. ${ }^{11}$

TURBT can be replaced by fulguration (without sample removal) in most cases of small low-grade lesions (consensus, LE: 2b GR: B), and this practice is accepted without restraint, as it has been shown to be feasible, safe, and cost-effective. ${ }^{55-57}$

\section{Intravesical therapy}

During the consensus, the panel used a practical definition for risk stratification proposed by the International Bladder Cancer Group, which divides cases into low-, intermediate-, and high-risk diseases based on the risk of recurrence and disease progression. ${ }^{58}$ Low-risk cases are comprised of a single lesion, pTa and low-grade tumors. Intermediate risk cases are recurrent or multiple low-grade pTa tumors. High-risk patients are those presenting with PT1 or high-grade tumors with or without CIS.

The indicated treatment in patients with low-risk, non-muscle-invasive disease after initial TURBT is single, immediate instillation of intravesical chemotherapy (IVC) (consensus, LE: 1a GR: A), except for those patients with bladder perforation after TURBT. Three meta-analyses with more than 2,000 patients each showed that a single dose of IVC is superior to resection only in NMIBC, as it prevents recurrence in up to $38 \%$ of cases and might decrease the 5 -year recurrence rate in approximately $10 \% .{ }^{59-61}$ In patients with an indication for a single instillation of IVC, the best drug to be administered is mitomycin C or gemcitabine (consensus, LE: 1b GR: A). Randomized studies have shown benefits for both medications, ${ }^{62,63}$ but there is no robust evidence supporting the superiority of either one. Unfortunately, mitomycin $C$ is not widely available in Brazil; therefore, gemcitabine is the most recommended. Studies with gemcitabine have shown a substantial $12 \%$ reduction in recurrence rate, but no difference in progression compared to placebo, ${ }^{61}$ and a safer profile compared to mitomycin $\mathrm{C}^{64}$

The treatment indicated in patients with intermediate-risk and high-risk non-muscle- invasive disease after initial TURBT is Bacillus Calmette-Guérin (BCG) (consensus, LE: 1a GR: A). Intravesical BCG is considered first-line therapy, especially in high-risk patients, showing a significant reduction of tumor recurrence and progression, and improved diseasespecific survival, superior to those of TURBT alone and IVC. ${ }^{65-70}$ Induction with BCG consists in 6 weekly treatments, and maintenance once a week for three weeks, at months 3, 6, 12, 18, 24, 30, and 36. ${ }^{71}$

Patients with non-muscle-invasive intermediate- and high-risk disease with an indication of intravesical therapy (IVT) with BCG should receive maintenance treatment with BCG (consensus, LE: 1a GR: A). Maintenance with BCG downshifts and potentially reduces progression risk, showing significantly lower recurrence than mitomycin $\mathrm{C}$ alone, intravesical epirubicin alone or a combination of epirubicin and interferon in intermediate- and high-risk patients. ${ }^{65-68,72-75}$

Maintenance should be used for one year in intermediate-risk patients (consensus, LE: 1a GR: A) because BCG maintenance is superior to mitomycin $C$ in progression prevention only if it is used in this manner. ${ }^{76}$ High-risk patients require three years of maintenance (consensus, LE: 1b GR: A) to significantly decrease tumor recurrence rate and progression and mortality. ${ }^{71,77-79}$

The appropriate dose of BCG (strain Moreau, Rio de Janeiro) to be administered is $80 \mathrm{mg}$ or its equivalent (consensus, LE: 5 GR: D), which is the full dose. A retrospective analysis comparing the TICE and Moreau strains did not show any difference in recurrence or progression to MIBC between the treatments. ${ }^{80}$ Dose reduction is appropriate in most selected cases for patients treated with BCG in order to reduce side effects (recommendation, LE: 1b GR: A), as a one-third dose is as effective as the full dose in intermediateand high- risk patients - but inferior in patients with multifocal tumors - with a lower toxicity. ${ }^{81,82}$

In the absence of BCG, in patients with intermediate-risk and high-risk disease, the best treatment option is IVC (consensus, LE: 1a GR: A) with maintenance therapy (consensus, LE: 1b GR: A). Mitomycin $C$ was shown to be efficient in decreasing recurrence and progression; however, it is inferior to BCG. ${ }^{66}$ Chemohyperthermia with mitomycin C offers additional benefits with a higher rate of reduction in recurrence compared to mitomycin alone. ${ }^{83}$ Intravesical gemcitabine shows comparable results with BCG in intermediate-risk patients but a higher recurrence rate in high-risk patients. ${ }^{84,85}$ Evidence of maintenance therapy with IVC is still not clear. Individual randomized trials have shown a decrease in recurrence rates. ${ }^{86-88}$ However, the results from other studies and meta-analyses did not demonstrate improvement in recurrence, progression, or survival. ${ }^{89-91}$ Maintenance with IVC should be used for up to one year for intermediate-risk patients (consensus, LE: 1b GR: A), with the aim of increasing disease-free survival (DFS), ${ }^{92}$ and for three years for high-risk patients (recommendation, LE: 5 GR: D).

\section{Follow-up NMIBC}

Regardless of the risk group, a follow-up cystoscopy is indicated 3-4 months after the initial TUR (with or 
without adjuvant BCG) in NMIBC patients (consensus, LE: $2 b$ GR: B). The importance of follow-up is to detect recurrence and/or progression as early as possible. Recurrence at 3 months is considered the main prognostic factor. ${ }^{93}$ Low-grade tumors present a $50 \%$ recurrence rate ${ }^{94}$ and high-grade tumors a 15$40 \%$ progression rate. ${ }^{95}$

The evaluation of the UUT should be performed only in high-risk patients (recommendation, LE: 4 GR: C) and annually for up to 5 years (recommendation, LE: 4 GR: C), as the chance of developing upper tract urothelial carcinoma (UTUC) after bladder cancer is approximately $5 \% .{ }^{96}$

Urinary cytology has a role in NMIBC follow-up in cases of high-risk tumors (recommendation, LE: 3a GR: B), as cytology has lower sensitivity in lowgrade tumors. ${ }^{97}$

In cases of urothelial CIS, we indicated performing random vesical biopsies during follow-up cystoscopy (recommendation, LE: 4 GR: C) because CIS can be difficult to visualize. Moreover, CIS is a high-risk tumor, and random biopsies increase the chance of diagnosis. ${ }^{34-37}$

The panel does not routinely recommend, in clinical practice (outside of research protocols), any type of urinary molecular biomarkers (e.g., FISH, NMP22) in NMIBC follow- up (recommendation, LE: 3a GR: B). Although it seems very promising data, the cost- effectiveness of these markers is still limited. ${ }^{97}$

\section{Failure after BCG}

BCG response is an important prognostic factor. Approximately $40 \%$ of patients will not respond to $B C G,{ }^{(98)}$ of which $60 \%$ will progress to invasive disease. ${ }^{90,100}$ Non-responder patients are classified as follows: refractory/unresponsive, with persistent highgrade disease despite 6 months of adequate therapy (induction and maintenance cycle), or any stage or grade progression within 3 months after the first cycle of BCG or recurring for up to 6 months; recurrent, with recurrent high-grade disease after 6 months of response with adequate therapy; and intolerant, with persistent disease due to the impossibility of adequate therapy because of high toxicity. ${ }^{101,102}$

In high-risk patients with refractoriness/unresponsiveness to IVT with BCG, the best- recommended treatment is radical cystectomy (RC) (consensus, LE: 2b GR: B). Patients who failed first-line BCG therapy should not be re-exposed to BCG unless unfit or unwilling to undergo cystectomy. In these cases, the standard of care is radical cystectomy. ${ }^{103,104}$ There is some evidence for successful IVC treatment in patients with refractory/non-responsive disease, but no study has yet compared IVC to cystectomy. Valrubicin for BCG-refractory CIS shows $21 \%$ complete response and an $87.7 \%$ recurrence rate. ${ }^{105}$ Treatment with intravesical gemcitabine in these cases provides only $20 \%$ RFS in one year. ${ }^{106}$ Intravenous immunotherapy with pembrolizumab showed $28 \%$ complete response at the time of last follow-up (14 months) in patients with BCG-unresponsive disease associated with CIS and its indication was recently approved in this scenario. This data was not available at the time of the consensus meeting.

In patients with recurrent disease after complete response following IVT with BCG, the best recommended treatment is BCG re-exposure (consensus, LE: 2b GR: B), with full dose induction and maintenance (consensus, LE: 2b GR: B) if the recurrence occurred at least 1 year following the last BCG cycle, as the previous treatment does not preclude the new course of BCG showing similar cancer-free rates between retreatment and first treatment. ${ }^{107} \mathrm{Re}$ - exposure to BCG shows significant recurrence-free and progression-free survival ${ }^{108}$ and a high rate of complete response. ${ }^{109}$ Patients who recurred after BCG treatment have a $20 \%$ chance of responding to BCG again. ${ }^{110}$ If the recurrence occurred up to 1 year following the initial treatment, the ideal treatment is cystectomy. In patients not eligible for or not willing to undergo $\mathrm{RC}$, the option is IVC. High-risk patients should be treated with $\mathrm{RC}^{1111}$ if the patient is not eligible or the treatment is rejected by the patient, inclusion in clinical studies or other IVC could be considered.

In patients with BCG therapy failure due to intolerance or lack of suitability for RC, the best recommended treatment is IVC (consensus, LE: 5 GR: D) because it has a better safety profile despite its inferior results. ${ }^{73}$

\section{Failure after IVC}

In patients with low-grade (recurrent or otherwise) disease, and patients who progressed to high-grade disease after IVC (single dose post-TUR), the best-recommended treatment is new resection and intravesical BCG induction and maintenance (consensus, LE: 1a GR: A). Low-grade patients with recurrence are considered intermediate-risk, and those with progression, high-risk. For both situations, patients should undergo TUR and be treated with intravesical BCG, as it has been shown to be superior to chemotherapy when administered with maintenance, presenting a 32\% decrease in recurrence and a 34\% decrease in progression rate in patients. ${ }^{66,73}$

In patients with pre-existing high-grade disease, those currently with recurrent (low grade) or for those who recurred but maintained high-grade disease after IVC (induction and maintenance), the best-recommended treatment is new resection and intravesical BCG - induction and maintenance (consensus, LE: 1a GR: A). For intermediate- and high-risk patients, the recommended first-line treatment is BCG with induction and maintenance after TUR. If for any reason they were treated with IVC, which shows inferior results, ${ }^{66,73}$ at recurrence they should receive BCG because it is the most optimal treatment.

\section{RC in NMIBC}

$\mathrm{RC}$ is the standard treatment for MIBC. ${ }^{112}$ In NMIBC, $\mathrm{RC}$ should be indicated as a therapeutic option in patients with high-risk Ta, T1, and CIS based on the substantial risks of recurrence and progression to muscle-invasive disease. It can be performed after 
NMIBC diagnosis or after BCG failure, depending on the aggressiveness of the disease. ${ }^{113}$ CIS is a highgrade disease with a risk of progression occurring in up to $53 \%$ of patients. ${ }^{114}$ Isolated CIS can positively respond to $B C G$ therapy ${ }^{115}$ and $R C .{ }^{116} \mathrm{RC}$ is indicated for high-risk non-responsive/refractory patients or those intolerant to intravesical therapy, with isolated CIS or without associated CIS (consensus, LE: 2b GR: B), particularly for those who recurred early. Surgery must be performed within 2 years because DSS is directly related to the delay of RC. ${ }^{104,117}$ Cystectomy should be considered in cases with associated CIS after staging-TUR or after refractory or intolerance of BCG (recommendation, LE: 2b GR: B), as it shows high cancer-specific survival, up to $92 \%$ in 10 years follow-up. ${ }^{118}$ High-risk patients without CIS but presenting lymphovascular invasion with T1 disease, a histological variant, T1 disease on repeat TUR, or high-volume multifocal high-grade disease are also candidates for RC after TUR. ${ }^{119}$

\section{$\mathrm{RC}$ in MIBC}

RC with lymphadenectomy is the standard treatment for MIBC without distant metastasis, with up to $60 \%$ rate of cure for pT3 disease and $30 \%$ in pT4 or low-volume lymph node-positive pN1,112 providing the highest rates of cure and lowest risk of recurrence. ${ }^{120-122} \mathrm{RC}$ is a complex surgery; the expertise of the medical team should always be considered in the RC indication and urinary diversion (UD) technique decision. For this reason, preference should be given to centers with large surgical volumes and an uro-oncological team, as the literature shows the benefit of centralized care for UBC, demonstrating better OS at high- volume centers, with lower positive surgical margins ${ }^{123-125}$ (consensus, LE: 2a GR: B). Furthermore, RC is associated with important hospitalization costs and significant in-hospital mortality, $^{126}$ imposing risks that could discourage professionals from performing the procedure, especially on older patients with comorbidities, despite its potential benefits ${ }^{127}$ and evidence that age should not be a factor for contraindication, as literature shows acceptable complications and mortality rates of RC with UD in octogenarians. ${ }^{128}$ The enhanced recovery after surgery (ERAS) protocol is indicated in cases of $\mathrm{RC}$ because it reduces the incidence of complications with lower bleeding and fewer readmissions, reduces the hospital internment period by 10 days, ${ }^{129}$ and does not increase $\operatorname{costs}^{130}$ (consensus, LE: 2b GR: B).

Regarding the technique and extent of cystectomy in men, the removal of the bladder, prostate, seminal vesicles, portions of the distal ureters, and regional lymph nodes is indicated. Preservation of the prostate can be performed only in extremely selected cases with the aim of achieving better functional results because sparing it is associated with a 10 to $15 \%$ higher oncological failure rate. ${ }^{131} \mathrm{RC}$ in women should include the removal of the bladder, uterus, adjacent vagina, urethra, a portion of the distal ureters, and regional lymph nodes (consensus, LE: 5 GR: D).
Pelvic lymphadenectomy associated with RC has a potentially curative role ${ }^{111}$ and reflects the quality of the surgery. Lymph node involvement is related to a higher recurrence of $\mathrm{BCa}$ and a shorter $\mathrm{OS}_{;}{ }^{112}$ therefore, it is used for staging, prognosis, and influencing subsequent therapy, e.g., the use of adjuvant therapy ${ }^{132}$ (consensus, LE: $2 \mathrm{~b}$ GR: B). The standard lymphadenectomy technique is preferentially recommended, including removal of lymph nodes to the intersection of the ureters (recommendation, LE: 5 GR: D), but there is no consensus for this practice. Extended lymphadenectomy is widely used, as it removes a greater number of lymph nodes with the advantage of identifying positive nodal involvement outside the standard technique area, ${ }^{133,134}$ but a comparative trial did not show significant difference in terms of mortality and time to recurrence. ${ }^{135}$

Regarding the decision of UD type after an RC, each type of diversion has its advantage and disadvantages. The decision should take into account the aspects of the disease, the patient's clinical conditions such as renal failure, liver function impairments, and bowel disorders, the surgeon's experience and the patient's preference (consensus, LE: 5 GR: D). Two main forms of diversions are used after cystectomy: nonorthotopic diversions (such as ureterocutaneostomy, ileal or colonic conduits, and continent conduits) and orthotopic diversions (such as orthotopic neobladder) (consensus, LE: 5 GR: D). There is no evidence to support the superiority of orthotopic or continent diversion over conduit diversion. ${ }^{136}$ Orthotopic neobladder is the closest choice to the natural bladder's function, and it seems to provide a better quality of life; ${ }^{137}$ however, it should be contraindicated in patients presenting with tumors with urethral invasion or positive urethral margins leading to urethrectomy (consensus, LE: 4 GR: C). In those cases, heterotopic continent bladder replacement (pouch) could be an option. ${ }^{138}$ Patients undergoing orthotopic neobladder with urethral involvement have a 0.5 to $17 \%$ recurrence rate. ${ }^{139-142}$ Therefore, after treatment with the curative intent for MIBC where the urethra has not been resected, we recommend regular follow-up of this region with examination defined on a per-case basis (recommendation, LE: 4 GR: C).

Short-term mortality rates show no difference among the types of urinary reconstruction performed. ${ }^{143,144}$ Oncological outcomes, such as all-cause and cancerspecific mortality, ${ }^{145}$ are also not impacted according to the type of UD chosen (consensus, LE: $2 b$ GR: B).

Most post cystectomy complications are related to UD, especially in patients with American Society of Anesthesiologists (ASA) scores higher than $3 .{ }^{146} \mathrm{Cu}$ taneous ureterostomy (CU) should be offered to patients as a form of UD in selected cases during intraoperative complications or clinical conditions (consensus, LE: 2b GR: B). CU requires shorter operative and hospitalization times and less blood transfusion compared to ileal conduit, ${ }^{147,148}$ enabling cystectomy in high-risk patients. However, long-term use of ureteral catheters is advised to avoid stenosis. 
In patients submitted to pelvic irradiation before cystectomy, as in bladder-sparing treatment modality protocols, the decision of the type of UD has no interference (consensus, LE: 5 GR: D). The basic principle of surgery is not to use irradiated tissue; however, with new protocols, tissues are usually spared, allowing the performance of any type of diversion. Radiotherapy cannot be considered a contraindication for UD, but there has been no formal comparison made between UD types and radiotherapy protocols. ${ }^{149}$ Prior pelvic radiotherapy does not increase complication rates of RC. ${ }^{150}$ The part of the intestine to be used in the diversion will depend on the state of the organs observed during surgery. ${ }^{151}$

Partial cystectomy can be attractive as a lower complexity procedure, with lower morbidity compared to RC; ;152,153 however, it should be avoided in both non-muscle- invasive and muscle-invasive tumors (consensus). Partial cystectomy should be an exception because it is associated with a high recurrence rate. ${ }^{154-156}$ Only in patients with T2 disease, with a solitary lesion in an area amenable to wide resection, with clear margins. This refers to open or minimally invasive procedures and not endoscopic resection. Some selected cases can be evaluated for partial cystectomy, such as solitary tumors without associated CIS located in a position that is amenable to wide excision. ${ }^{152,157}$

After curative treatment of MIBC with bladder preservation (e.g., TMT, radiotherapy, partial cystectomy or TURBT), the panel recommends regular cystoscopy in the follow-up (consensus). These patients still present a higher recurrence rate compared to RC and should receive life-long follow-up ${ }^{158}$ (LE: 4 GR: C).

\section{Preservation treatment in localized BCa}

TMT is a strategy of preservation therapy for the bladder in MIBC, and it could be considered an option in high-risk T1 for patients who failed BCG treatment, after second line chemotherapy and for those patients not candidates for cystectomy. This procedure consists of maximum TURBT followed by chemotherapy-associated radiotherapy (consensus, LE: 1c GR: A). Complete response rate may be achieved by 50 to $70 \%$ of patients treated with TMT, ${ }^{159-162}$ the 5 -year OS by $57 \%$ of patients and the 10 -year OS by $36 \%$ of patients. ${ }^{162}$

Re-TURBT is not mandatory, but it is the recommendation of this panel to confirm maximum resection (recommendation, LE: $4 \mathrm{GR}$ : C), which is one of the most important prognostic factors affecting OS in TMT. ${ }^{163}$

TMT is considered in selected cases of localized BCa and should be recommended according to the patient's preference but is unfit for patients due to age $^{164}$ or comorbidities (consensus, LE: $2 b$ GR: B), as $\mathrm{RC}$ involves risks and might impact quality of life. The ideal patient for multimodal therapy is as follows: T2, single tumor, with a favorable location that can undergo maximum resection in TUR, without CIS, with- out hydronephrosis, with urothelial histology, with tumors smaller than $5 \mathrm{~cm}$ and good bladder function (consensus, LE: 2b GR: B), in which the treatment will provide significant benefit ${ }^{(165)}$ with comparable 5- and 10-year OS rates to RC with lymphadenectomy. ${ }^{163,165-169}$ TMT in primary or recurrent high-risk T1 bladder-cancer patients provides better 5-year disease-specific survival (DSS) compared to only radiotherapy. ${ }^{170}$ In a small case series of 18 NMIBC patients ith recurrent and progressive disease, TMT provided a 7 -year DSS for $70 \%$ and OS for $58 \%$ of patients. ${ }^{171}$ This consensus did not include voting on follow-up recommendations for patients treated with TMT.

CIS, multifocality, hydronephrosis, and/or T3/T4 are contraindications for multimodal treatment with intention of bladder preservation (recommendation, LE: 4 GR: C). However, patients with T3/T4 are not absolute contraindications; they present inferior results compared to patients with T2 or lower, ${ }^{168}$ but we should consider that RC in those patients does not offer important oncological outcomes either. The results for T3b-T4 or $\mathrm{N}+$ and $\mathrm{M} 0$ patients treated with TMT show 30\% OS, ${ }^{172}$ making it an alternative for those not eligible for surgery. Patients with hydronephrosis present a worse complete response rate but no difference in OS compared to patients without hydronephrosis. ${ }^{168}$

We recommend a complete tumoricidal dose of radiotherapy (55-66Gy) in the preservation therapy (consensus, LE: 2a GR: B), including the irradiation of pelvic lymphatic drainage (consensus, LE: 2a GR: B), targeting occult pelvic lymph node involvement. ${ }^{(173)}$ Patients with clinical contraindication to or not willing to undergo RC should receive a full-dose, straight course of radiotherapy. ${ }^{174,175}$ Split-course radiotherapy (induction with a dose of 40-46Gy, revaluation with cystoscopy and an additional 20-26Gy in the absence of neoplasia) was not the preferred treatment scheme in this consensus, ${ }^{176}$ as $40 \mathrm{~Gy}$ is a subclinical dose, maximum tumor response may take up to three months, and the absence of response before this period does not conclude ineffectiveness. Considering the complete dose and evaluation versus split dose and evaluation, there is some evidence that the first offers better outcomes, with less salvage cystectomy rates, better complete response rates, and better overall survival. ${ }^{168}$ Nonetheless, in the discussion held by the consensus, it was considered that split course treatment could be offered as an alternative at the physician's discretion.

Treatment of locally advanced BCa encompasses neoadjuvant chemotherapy followed by RC. In general, there is no indication for adjuvant radiotherapy in bladder cancer (recommendation, LE: 4 GR: C), except for patients presenting with pT3-pT4N+ with positive margins, where adjuvant radiotherapy could provide improvement in OS, ${ }^{177-179}$ and for non-urothelial bladder tumors, with $78 \%$ of local-regional control. ${ }^{180}$ The recommendations for systemic chemotherapy were discussed in a separate manuscript. 
When there is an indication of radical radiotherapy (with or without chemotherapy) or adjuvant, the ideal technique for radiation dose administration is intensity-modulated radiation (IMRT) and image-guided radiotherapy (IGRT) (consensus, LE: 5 GR: D) because these two techniques complement each other, as IGRT helps with accurately targeting, and together the two therapies limit the high dose regions to the targets, sparing normal tissue. ${ }^{181}$ The minimally acceptable technique is conformal radiotherapy (RT3D), which can be used with IGRT (recommendation, LE: 5 GR: D).

\section{CONCLUSION}

Effective treatment and optimal follow-up are the primary means for minimizing recurrence and progression in urothelial carcinoma, significantly changing the patient's prognosis. The expertise of a multidisciplinary team with the best evidence in the medical literature available should be sought to improve the treatment of oncologic patients and offer better care.

\section{ABBREVIATIONS:}

American Society of Anesthesiologists (ASA); Bacillus Calmette-Guérin (BCG);

Bladder cancer (BCa);

Brazilian Society of Clinical Oncology (SBOC); Brazilian Society of Radiotherapy (SBRT); Brazilian Society of Urology (SBU);

Carcinoma in situ (CIS); Computed tomography (CT); Cutaneous ureterostomy (CU); Disease-free survival (DFS); Disease-specific survival (DSS);

Enhanced recovery after surgery (ERAS); Grade of recommendation (GR);

Intravesical chemotherapy (IVC); Intravesical therapy (IVT);

Latin American Cooperative Oncology Group (LACOG); Level of evidence (LE);

Magnetic resonance imaging (MRI); Muscle-invasive bladder cancer (MIBC);

Non-muscle-invasive bladder cancer (NMIBC); Overall survival (OS);

Radical Cystectomy (RC); Recurrence-free survival (RFS); Repeating TURBT (re-TURBT); Transurethral resection (TUR);

Transurethral resection of bladder tumor (TURBT); Tri-modality therapy (TMT);

Upper urinary tract (UUT); Urothelial carcinoma (UC); Urothelial bladder carcinoma (UBC); Urinary diversion (UD):

With white light cystoscopy (WLC).

\section{FUNDING SOURCE}

Funding to support the preparation of this manuscript was provided by MSD, Roche, Janssen, and Pierre Fab- re Laboratories. The authors take full responsibility for the content and conclusions stated in this manuscript. MSD, Roche, Janssen, and Pierre Fabre Laboratories did not influence the content of this publication.

\section{AUTHORS' CONTRIBUTIONS}

All authors participated in the conceptualization, review, and revision of this manuscript. In addition, all authors have read and approved the final version of this manuscript.

\section{REFERENCES}

1. World Health Organization (WHO). Cancer today. GLOBOCAN 2018 [Internet]. Geneva: WHO; 2018; [access in 2019 May 10]. Available from: http://gco.iarc.fr/today/home

2. Santos MO. Estimativa 2018: incidência de câncer no Brasil. Rev Bras Cancerol [Internet]. 2018; [cited 2019 May 10]; 61(1):119-20. Available from: https://rbc.inca.gov.br/revista/index.php/ revista/article/view/115

3. Cumberbatch MGK, Jubber I, Black PC, Esperto F, Figueroa JD, Kamat AM, et al. Epidemiology of bladder cancer: a systematic review and contemporary update of risk factors in 2018. Eur Urol. 2018 Dec;74(6):784-95.

4. Yee DS, Ishill NM, Lowrance WT, Herr HW, Elkin EB. Ethnic differences in bladder cancer survival. Urology. 2011 Sep;78(3):544-9.

5. Fajkovic H, Halpern JA, Cha EK, Bahadori A, Chromecki TF, Karakiewicz PI, et al. Impact of gender on bladder cancer incidence, staging, and prognosis. World J Urol. 2011 Aug;29(4):457-63.

6. Lammers RJ, Witjes WP, Hendricksen $\mathrm{K}$, Caris CT, Janzing-Pastors MH, Witjes JA. Smoking status is a risk factor for recurrence after transurethral resection of non-muscle- invasive bladder cancer. Eur Urol. 2011 Jul;60(4):713-20.

7. Yafi FA, Aprikian AG, Chin JL, Fradet Y, Izawa J, Estey E, et al. Contemporary outcomes of 2287 patients with bladder cancer who were treated with radical cystectomy: a Canadian multicentre experience. BJU Int. 2011 Aug;108(4):539-45.

8. Heidegger I, Borena W, Pichler R. The role of human papilloma virus in urological malignancies. Anticancer Res. 2015 May;35(5):2513-9.

9. Burger M, Catto JW, Dalbagni G, Grossman HB, Herr $\mathrm{H}$, Karakiewicz $\mathrm{P}$, et al. Epidemiology and risk factors of urothelial bladder cancer. Eur Urol. 2013 Feb;63(2):234-41.

10. Bryan RT, Collins SI, Daykin MC, Zeegers MP, Cheng KK, Wallace DM, et al. Mechanisms of recurrence of Ta/T1 bladder cancer. Ann R Coll Surg Engl. 2010 Sep;92(6):519-24.

11. Woldu SL, Bagrodia A, Lotan Y. Guideline of guidelines: non-muscle-invasive bladder cancer. BJU Int. 2017 Mar;119(3):371-80. 
12. Kaufman DS, Shipley WU, Feldman AS. Bladder cancer. Lancet. 2009 Jul;374:239-49.

13. Abdollah F, Gandaglia G, Thuret R, Schmitges J, Tian $Z$, Jeldres $C$, et al. Incidence, survival and mortality rates of stage-specific bladder cancer in United States: a trend analysis. Cancer Epidemiol. 2013;37(3):219-25.

14. Philips B, Sackett D, Badenoch D, Straus S, Haynes B, Dawes M. Oxford Centre for Evidence-based Medicine (CEBM) - levels of evidence (March 2009) [Internet]. Oxford: CEBM; 2009; [access in 2019 May 10]. Available from: https://www.cebm.net/2009/06/ oxford-centre-evidence-based-medicine-levels-evidence-march-2009/

15. Larré S, Catto JWF, Cookson MS, Messing EM, Shariat SF, Soloway MS, et al. Screening for bladder cancer: rationale, limitations, whom to target, and perspectives. Eur Urol. 2013;63(6):1049-58.

16. Kishi K, Hirota T, Matsumoto K, Kakizoe T, Murase T, Fujita J. Carcinoma of the bladder: a clinical and pathological analysis of 87 autopsy cases. J Urol. 1981 Jan;125(1):36-9.

17. Vickers AJ, Bennette C, Kibel AS, Black A, Izmirlian G, Stephenson AJ, et al. Who should be included in a clinical trial of screening for bladder cancer? A decision analysis of data from the prostate, lung, colorectal and ovarian cancer screening trial. Cancer. 2013 Jan;119(1):143-9.

18. Van DerAa MS, Bangma EW, Van Rhijn CH, Zwarthoff BWG, Van Der Kwast ECTH. Cystoscopy revisited as the gold standard for detection of bladder cancer recurrences: diagnostic review bias in a prospective randomised trial. J Urol. 2009 Apr;8(4):374.

19. Van Der Aa MN, Steyerberg EW, Sen EF, Zwarthoff EC, Kirkels WJ, Van Der Kwast TH, et al. Patients' perceived burden of cystoscopic and urinary surveillance of bladder cancer: a randomized comparison. BJU Int. 2008 May;101(9):1106-10.

20. Xiong Y, LiJ, MaS, Ge J, Zhou L, Li D, et al. A meta-analysis of narrow band imaging for the diagnosis and therapeutic outcome of non-muscle invasive bladder cancer. PLoS One. 2017 Feb;12(2):e0170819.

21. Schumacher MC, Holmäng $S$, Davidsson T, Friedrich B, Pedersen J, Wiklund NP. Transurethral resection of non-muscle-invasive bladder transitional cell cancers with or without 5-aminolevulinic acid under visible and fluorescent light: results of a prospective, randomised, multicentre study. Eur Urol. 2010 Feb;57(2):293-9.

22. Schmidbauer J, Witjes F, Schmeller N, Donat R, Susani M, Marberger M. Improved detection of urothelial carcinoma in situ with hexaminolevulinate fluorescence cystoscopy. J Urol. 2004 Jan;171(1):135-8.

23. Jichlinski $P$, Leisinger $\mathrm{HJ}$. Fluorescence cystoscopy in the management of bladder cancer: a help for the urologist!. Urol Int. 2005;74(2):97-101.
24. Tatsugami K, Kuroiwa K, Kamoto T, Nishiyama H, Watanabe J, Ishikawa S, et al. Evaluation of narrow-band imaging as a complementary method for the detection of bladder cancer. J Endourol. 2010;24(11):1807-11.

25. Filbeck T, Roessler W, Knuechel R, Straub M, Kiel $\mathrm{HJ}$, Wieland WF. Clinical results of the transurethreal resection and evaluation of superficial bladder carcinomas by means of fluorescence diagnosis after intravesical instillation of 5-aminolevulinic acid. J Endourol. 1999;13(2):117-21.

26. Liu JJ, Droller MJ, Liao JC. New optical imaging technologies for bladder cancer: considerations and perspectives. J Urol. 2012 Aug;188(2):361-8.

27. Cowan NC. CT urography for hematuria. Nat Rev Urol. 2012 Mar;9(4):218-26.

28. Kantachuvesiri P, Mohammed A, Parkinson RJ. A retrospective study on the investigation of upper tract transitional cell carcinoma - are we detecting enough cases? Eur J Surg Oncol. 2014 Nov;40(11):S180.

29. Lang EK, Macchia RJ, Thomas R, Ruiz-Deya G, Watson RA, Richter F, et al. Computerized tomography tailored for the assessment of microscopic hematuria. J Urol. 2002 Feb;167(2 Pt 1):547-54.

30. Jinzaki M, Matsumoto K, Kikuchi E, Sato K, Horiguchi $Y$, Nishiwaki $Y$, et al. Comparison of CT urography and excretory urography in the detection and localization of urothelial carcinoma of the upper urinary tract. AJR Am J Roentgenol. 2011 May; 196(5):1102-9.

31. Takahashi N, Glockner JF, Hartman RP, King BF, Leibovich BC, Stanley DW, et al. Gadolinium enhanced magnetic resonance urography for upper urinary tract malignancy. J Urol. 2010 Apr;183(4):1330-65.

32. Rouprêt M, Babjuk $M$, Compérat $E$, Zigeuner $R$, Sylvester R, Burger M, et al. European guidelines on upper tract urothelial carcinomas: 2013 update. Eur Urol. 2013 Jun;63(6):1059-71.

33. Tang DH, Chang SS. Management of carcinoma in situ of the bladder: best practice and recent developments. Ther Adv Urol. 2015 Dec;7(6):351-64.

34. Van Der Meijden A, Oosterlinck W, Brausi M, Kurth $\mathrm{KH}$, Sylvester R, Balincourt C. Significance of bladder biopsies in Ta, $\mathrm{T} 1$ bladder tumors: a report from the EORTC Genito- Urinary Tract Cancer Cooperative Group. EORTC-GU Group Superficial Bladder Committee. Eur Urol. 1999 Apr;35(4):267-71.

35. Hara T, Takahashi M, Gondo T, Nagao K, Ohmi C, Sakano S, et al. Risk of concomitant carcinoma in situ determining biopsy candidates among primary non-muscle-invasive bladder cancer patients: retrospective analysis of 173 Japanese cases. Int J Urol. 2009 Mar;16(3):293-8.

36. Otsuka M, Taguchi S, Nakagawa T, Morikawa T, Maekawa S, Miyakawa J, et al. Clinical significance of random bladder biopsy in primary T1 bladder cancer. Mol Clin Oncol. 2018 May;8(5):665-70. 
37. Kumano M, Miyake H, Nakano Y, Fujisawa M. Significance of random bladder biopsies in non-muscle invasive bladder cancer. Curr Urol. 2013;7:57-61.

38. Dahm P, Gschwend JE. Malignant non-urothelial neoplasms of the urinary bladder: a review. Eur Urol. 2003 Dec;44(6):672-81.

39. Aragon-Ching J, Henson D. Differences in survival among non-urothelial bladder cancers: analyses of SEER 1988-2008. J Clin Oncol. 2018;36(Suppl 6):S425.

40. Furuse $\mathrm{H}$, Ozono S. Transurethral resection of the bladder tumour (TURBT) for non-muscle invasive bladder cancer: basic skills. Int J Urol. 2010 Aug;17(8):698-9.

41. Rolevich A, Minich A, Nabebina T, Polyakov S, Krasny S, Sukonko O. Surgeon has a major impact on long-term recurrence risk in patients with non-muscle invasive bladder cancer. Cent European J Urol. 2016;69(2):170-7.

42. Brausi M, Collette L, Kurth K, Van Der Meijden AP, Oosterlinck W, Witjes JA, et al. Variability in the recurrence rate at first follow-up cystoscopy after TUR in stage Ta T1 transitional cell carcinoma of the bladder: a combined analysis of seven EORTC studies. Eur Urol. 2002;41(5):523-31.

43. Mariappan P, Zachou A, Grigor KM, Edinburgh Uro-Oncology Group. Detrusor muscle in the first, apparently complete transurethral resection of bladder tumour specimen is a surrogate marker of resection quality, predicts risk of early recurrence, and is dependent on operator experience. Eur Urol. 2010;57:843-9.

44. Gontero P, Sylvester R, Pisano F, Joniau S, Oderda $M$, Serretta V, et al. The impact of re- transurethral resection on clinical outcomes in a large multicentre cohort of patients with T1 high-grade/Grade 3 bladder cancer treated with bacille CalmetteGuérin. BJU Int. 2016 Jul;118(1):44-52.

45. Donat SM, Wei DC, McGuire MS, Herr HW. The efficacy of transurethral biopsy for predicting the long-term clinical impact of prostatic invasive bladder cancer. J Urol. 2001 May;165(5):1580-4.

46. Brant A, Daniels M, Chappidi MR, Joice GA, Sopko NA, Matoso A, et al. Prognostic implications of prostatic urethral involvement in non-muscle-invasive bladder cancer. World J Urol. 2019 Dec;37(12):2683-9.

47. Nixon RG, Chang SS, Lafleur BJ, Smith JA, Cookson MS. Carcinoma in situ and tumor multifocality predict the risk of prostatic urethral involvement at radical cystectomy in men with transitional cell carcinoma of the bladder. J Urol. 2002;167:502-5.

48. Mungan MU, Canda AE, Tuzel E, Yorukoglu K, Kirkali Z. Risk factors for mucosal prostatic urethral involvement in superficial transitional cell carcinoma of the bladder. Eur Urol. 2005 Nov;48(5):760-3.

49. Luo $S$, Lin $Y$, Zhang W. Does simultaneous transurethral resection of bladder tumor and prostate affect the recurrence of bladder tumor? A meta-analysis. J Endourol. 2011 Feb;25(2):291-6.
50. Tsivian A, Shtricker A, Sidi AA. Simultaneous transurethral resection of bladder tumor and benign prostatic hyperplasia: hazardous or a safe timesaver? J Urol. 2003;170(6 Pt 1):2241-3.

51. Shim JS, Choi H, Noh TI, Tae JH, Yoon SG, Kang $\mathrm{SH}$, et al. The clinical significance of a second transurethral resection for T1 high-grade bladder cancer: results of a prospective study. Korean J Urol. 2015 May;56(6):429-34.

52. Divrik RT, Sahin AF, Yildirim U, Altok M, Zorlu F. Impact of routine second transurethral resection on the long-term outcome of patients with newly diagnosed pT1 urothelial carcinoma with respect to recurrence, progression rate, and disease-specific survival: a prospective randomised clinical trial. Eur Urol. 2010 Aug;58(2):185-90.

53. Sha N, Xie L, Chen T, Xing C, Liu X, Zhang Y, et al. Impact of lymphovascular invasion on recurrence and progression rates in patients with pT1 urothelial carcinoma of bladder after transurethral resection. Onco Targets Ther. 2015;8:3401-6.

54. Streeper NM, Simons CM, Konety BR, Muirhead DM, Williams RD, O'Donnell MA, et al. The significance of lymphovascular invasion in transurethral resection of bladder tumour and cystectomy specimens on the survival of patients with urothelial bladder cancer. BJU Int. 2009 Feb;103(4):475-9.

55. Zare R, Grabe M, Hermann GG, Malmström PU. Can routine outpatient follow-up of patients with bladder cancer be improved? A multicenter prospective observational assessment of blue light flexible cystoscopy and fulguration. Res Rep Urol. 2018 Oct;10:151-7.

56. Guerra ÁR, Aparicio TF, Bayonas IB, Martínez AP, Guillermo VM, Peralta DJ, et al. Outpatient Holmium laser fulguration: a safe procedure for treatment of recurrence of non-muscle invasive bladder cancer. Actas Urol Esp. 2018 Jun;42(5):309-15.

57. Al-Awamlh BAH, Lee R, Chughtai B, Donat SM, Sandhu JS, Herr HW. A cost- effectiveness analysis of management of low-risk non-muscle-invasive bladder cancer using office-based fulguration. Urology. 2015 Feb;85(2):381-6.

58. Brausi M, Witjes JA, Lamm D, Persad R, Palou $\mathrm{J}$, Colombel $\mathrm{M}$, et al. A review of current guidelines and best practice recommendations for the management of nonmuscle invasive bladder cancer by the International Bladder Cancer Group. J Urol. 2011;186(6):2158-67.

59. Sylvester RJ, Oosterlinck W, Holmang S, Sydes MR, Birtle A, Gudjonsson S, et al. Systematic review and individual patient data meta-analysis of randomized trials comparing a single immediate instillation of chemotherapy after transurethral resection with transurethral resection alone in patients with stage pTa-pT1 urothelial carcinoma of the bladder: which patients benefit from the instillation?. Eur Urol. 2016 Feb;69(2):231-44. 
60. Abern MR, Owusu RA, Anderson MR, Rampersaud EN, Inman BA. Perioperative intravesical chemotherapy in non-muscle-invasive bladder cancer: a systematic review and meta-analysis. J Natl Compr Canc Netw. 2013 Apr;11(4):477-84.

61. Perlis N, Zlotta AR, Beyene J, Finelli A, Fleshner NE, Kulkarni GS. Immediate post- transurethral resection of bladder tumor intravesical chemotherapy prevents non-muscle-invasive bladder cancer recurrences: an updated meta-analysis on 2548 patients and quality- of-evidence review. Eur Urol. 2013;64:421-30.

62. Bosschieter J, Nieuwenhuijzen JA, Van Ginkel T, Vis AN, Witte B, Newling D, et al. Value of an immediate intravesical instillation of mitomycin $C$ in patients with non-muscle-invasive bladder cancer: a prospective multicentre randomised study in 2243 patients. Eur Urol. 2018 Feb;73(2):226-32.

63. Messing EM, Tangen CM, Lerner SP, Sahasrabudhe DM, Koppie TM, Wood Junior DP, et al. Effect of intravesical instillation of gemcitabine vs saline immediately following resection of suspected low-grade non-muscle-invasive bladder cancer on tumor recurrence: SWOG S0337 randomized clinical trial. JAMA. 2018;319:1880-8.

64. Addeo R, Caraglia M, Bellini S, Abbruzzese A, Vincenzi $B$, Montella $L$, et al. Randomized phase III trial on gemcitabine versus mytomicin in recurrent superficial bladder cancer: evaluation of efficacy and tolerance. J Clin Oncol. 2010 Feb;28(4):543-8.

65. Shang PF, Kwong J, Wang ZP, Tian J, Jiang L, Yang $K$, et al. Intravesical Bacillus CalmetteGuérin versus epirubicin for Ta and T1 bladder cancer. Cochrane Database Syst Rev. 2011 May;(5):CD006885.

66. Malmström PU, Sylvester RJ, Crawford DE, Friedrich $M$, Krege S, Rintala $E$, et al. An individual patient data meta-analysis of the long-term outcome of randomized studies comparing intravesical mitomycin $C$ versus bacillus CalmetteGuérin for non-muscle-invasive bladder cancer. Eur Urol. 2009 Aug;56(2):247-56.

67. Han RF, Pan JG. Can intravesical bacillus Calmette-Guerin reduce recurrence in patients with superficial bladder cancer? A meta-analysis of randomized trials. Urology. 2006 Jun;67(6):1216-23.

68. Sylvester RJ, Van Der MA, Lamm DL. Intravesical bacillus Calmette-Guerin reduces the risk of progression in patients with superficial bladder cancer: a meta-analysis of the published results of randomized clinical trials. J Urol. 2002 Nov;168(5):1964-70.

69. Shelley MD, Kynaston $H$, Court J, Wilt TJ, Coles $B$, Burgon $K$, et al. A systematic review of intravesical bacillus Calmette-Guerin plus transurethral resection vs transurethral resection alone in Ta and T1 bladder cancer. BJU Int. 2001 aug;88(3):209-16.
70. Shelley MD, Court JB, Kynaston H, Wilt TJ, Fish RG, Mason M. Intravesical Bacillus Calmette-Guerin in Ta and T1 bladder cancer. Cochrane Database Syst Rev. 2000;2000(4):CD001986.

71. Lamm DL, Blumenstein BA, Crissman JD, Montie JE, Gottesman JE, Lowe BA, et al. Maintenance bacillus Calmette-Guerin immunotherapy for recurrent TA, T1 and carcinoma in situ transitional cell carcinoma of the bladder: a randomized Southwest Oncology Group Study. J Urol. 2000 Apr;163(4):1124-9.

72. Chen S, Zhang N, Shao J, Wang X. Maintenance versus non-maintenance intravesical Bacillus Calmette-Guerin instillation for non-muscle invasive bladder cancer: a systematic review and meta-analysis of randomized clinical trials. Int J Surg. 2018 Apr;52:248-57.

73. Bohle A, Jocham D, Bock PR. Intravesical bacillus Calmette-Guerin versus mitomycin $C$ for superficial bladder cancer: a formal meta-analysis of comparative studies on recurrence and toxicity. J Urol. 2003 Jan;169(1):90-5.

74. Järvinen R, Kaasinen E, Sankila A, Rintala E, FinnBladder Group. Long-term efficacy of maintenance bacillus Calmette-Guérin versus maintenance mitomycin C instillation therapy in frequently recurrent TaT1 tumours without carcinoma in situ: a subgroup analysis of the prospective, randomized Finn Bladder I study with a 20-year follow-up. Eur Urol. 2009 Aug;56(2):260-5.

75. Shelley MD, Wilt TJ, Court J, Coles B, Kynaston H, Mason MD. Intravesical bacillus Calmette-Guerin is superior to mitomycin $C$ in reducing tumour recurrence in high-risk superficial bladder cancer: a meta-analysis of randomized trials. BJU Int. 2004 Mar;93(4):485-90.

76. Böhle A, Bock PR. Intravesical bacille CalmetteGuérin versus mitomycin $C$ in superficial bladder cancer: formal meta-analysis of comparative studies on tumor progression. Urology. 2004 Apr;63(4):682-7.

77. Oddens J, Brausi M, Sylvester R, Bono A, Van de Beek C, Van Andel G, et al. Final results of an EORTC-GU cancers group randomized study of maintenance bacillus Calmette-Guérin in intermediate- and high-risk Ta, T1 papillary carcinoma of the urinary bladder: one-third dose versus full dose and 1 year versus 3 years of maintenance. Eur Urol. 2013 Mar;63(3):462-72.

78. Sylvester RJ, Brausi MA, Kirkels WJ, Hoeltl W, Silva FC, Powell PH, et al. Long-term efficacy results of EORTC genito-urinary group randomized phase 3 study 30911 comparing intravesical instillations of epirubicin, bacillus Calmette-Guérin, and bacillus Calmette-Guérin plus isoniazid in patients with intermediate- and high-risk stage Ta T1 urothelial carcinoma of the bladder. Eur Urol. 2010 May;57(5):766-73. 
79. Leliveld AM, Bastiaannet E, Doornweerd BHJ, Schaapveld MI, Jong IJ. High-risk bladder cancer: current management and survival. Int Braz J Urol. 2011 Mar/Apr;37(2):203-12.

80. D'Andrea D, Gontero P, Machado A, Waksman R, Shariat S, Chade D. Comparative effectiveness of intravesical BCG-TICE and BCG-Moreau in patients with non-muscle invasive bladder cancer. Clin Genitourin Cancer. 2020 Feb;18(1):20-25.e2.

81. Martinez-Pineiro JA, Martinez-Pineiro L, Solsona $E$, Rodriguez RH, Gomez JM, Martin MG, et al. Has a 3-fold decreased dose of bacillus Calmette-Guerin the same efficacy against recurrences and progression of T1G3 and Tis bladder tumors than the standard dose? Results of a prospective randomized trial. J Urol. 2005 Oct;174(4 Pt 1):1242-7.

82. Martinez-Pineiro JA, Flores N, Isorna S, Solsona E, Sebastian JL, Pertusa C, et al. Long- term follow-up of a randomized prospective trial comparing a standard $81 \mathrm{mg}$ dose of intravesical bacille Calmette-Guerin with a reduced dose of $27 \mathrm{mg}$ in superficial bladder cancer. BJU Int. 2002 May;89(7):671-80.

83. Lammers RJ, Witjes JA, Inman BA, Leibovitch I, Laufer M, Nativ O, et al. The role of a combined regimen with intravesical chemotherapy and hyperthermia in the management of non-muscle-invasive bladder cancer: a systematic review. Eur Urol. 2011 Jul;60(1):81-93.

84. Bendary L, Khalil S, Shahin A, Nawar N. Intravesical gemcitabine versus bacillus calmette-guerin (BCG) in treatment of non-muscle invasive bladder cancer: short-term comparative study. J Urol. 2011 Apr;185(4):e664-e5.

85. Porena M, Del Zingaro M, Lazzeri M, Mearini L, Giannantoni A, Bini V, et al. Bacillus Calmette-Guérin versus gemcitabine for intravesical therapy in highrisk superficial bladder cancer: a randomised prospective study. Urol Int. 2010;84(1):23-7.

86. Koga H, Kuroiwa K, Yamaguchi A, Osada Y, Tsuneyoshi M, Naito S. A randomized controlled trial of short-term versus long-term prophylactic intravesical instillation chemotherapy for recurrence after transurethral resection of Ta/T1 transitional cell carcinoma of the bladder. J Urol. 2004 Jan;171(1):153-7.

87. Conrad S, Friedrich M, Schwaibold HP, U, Schildt $\mathrm{KW}$, Huland $\mathrm{H}$. Long term prophylaxis with Mitomycin C (MMC) further reduces tumor recurrence compared to short term prophylaxis with MMC or Bacillus Calmette-Guerin (BCG). J Urol. 2004 Apr;171(4):71.

88. Bouffioux C, Kurth KH, Bono A, Oosterlinck W, Kruger $\mathrm{CB}$, Pauw $\mathrm{M}$, et al. Intravesical adjuvant chemotherapy for superficial transitional cell bladder carcinoma: results of 2 European Organization for Research and Treatment of Cancer randomized trials with mitomycin $\mathrm{C}$ and doxorubicin comparing early versus delayed instillations and short-term versus long-term treatment. European Organization for Research and Treatment of Cancer Genitourinary Group. J Urol. 1995 Mar;153(3 Pt 2):934-41.
89. Tabayoyong WB, Kamat AM, O'Donnell MA, McKiernan JM, Ray-Zack MD, Palou J, et al. Systematic review on the utilization of maintenance intravesical chemotherapy in the management of non-muscle-invasive bladder cancer. Eur Urol Focus. 2018 Jul;4(4):512-21.

90. Okamura K, Kinukawa T, Tsumura Y, Otani T, Itoh H, Kobayashi $\mathrm{H}$, et al. A randomized study of short-versus long-term intravesical epirubicin instillation for superficial bladder cancer. Nagoya University Urological Oncology Group. Eur Urol. 1998;33:285-8.

91. Huland H, Kloppel G, Feddersen I, Otto U, Brachmann W, Hubmann $\mathrm{H}$, et al. Comparison of different schedules of cytostatic intravesical instillations in patients with superficial bladder carcinoma: final evaluation of a prospective multicenter study with 419 patients. J Urol. 1990 Jul;144(1):68-71.

92. Lundholm C, Norlen BJ, Ekman P, Jahnson S, Lagerkvist $\mathrm{M}$, Lindeborg $\mathrm{T}$, et al. A randomized prospective study comparing long-term intravesical instillations of mitomycin $\mathrm{C}$ and bacillus Calmette-Guerin in patients with superficial bladder carcinoma. J Urol. 1996 Aug;156(2 Pt 1):372-6.

93. Palou J, Rodríguez-Rubio F, Millán F, Algaba F, Rodríguez-Faba O, Huguet J, et al. Recurrence at three months and high-grade recurrence as prognostic factor of progression in multivariate analysis of T1G2 bladder tumors. Urology. 2009 Jun;73(6):1313-7.

94. May M, Brookman-Amissah S, Roigas J, Hartmann A, Störkel S, Kristiansen G, et al. Prognostic accuracy of individual uropathologists in noninvasive urinary bladder carcinoma: a multicentre study comparing the 1973 and 2004 World Health Organization classifications. Eur Urol. 2009 Mar;57(5):850-8.

95. Amin MB, McKenney JK, Paner GP, Hansel DE, Grignon DJ, Montironi R, et al. ICUD- EAU International Consultation on Bladder Cancer 2012: pathology. Eur Urol. 2013 Jan;63(1):16- 35.

96. Smith H, Weaver D, Barjenbruch O, Weinstein S, Ross Junior G. Routine excretory urography in follow-up of superficial transitional cell carcinoma of bladder. Urology. 1989 Oct;34(4):193-6.

97. Van Rhijn BW, Van Der Poel HG, Van Der Kwast TH. Urine markers for bladder cancer surveillance: a systematic review. Eur Urol. 2005 Jun;47(6):736-48.

98. Alhunaidi O, Zlotta AR. The use of intravesical BCG in urothelial carcinoma of the bladder. Ecancer Med Sci. 2019;13:905.

99. Solsona E, Iborra I, Dumont R, Rubio-Briones J, Casanova J, Almenar S. The 3-month clinical response to intravesical therapy as a predictive factor for progression in patients with high risk superficial bladder cancer. J Urol. 2000 Sep;164(3 Pt 1):685-9.

100.Van Gils-Gielen RJ, Witjes WP, Caris CT, Debruyne FM, Witjes JA, Oosterhof GO. Risk factors in carcinoma in situ of the urinary bladder. Urology. 1995;45:581-6. 
101.O'Donnell MA, Boehle A. Treatment options for BCG failures. World J Urol. 2006 Nov;24(5):481-7.

102.Herr HW, Dalbagni G. Defining bacillus Calmette-Guerin refractory superficial bladder tumors. J Urol. 2003 May;169(5):1706-8.

103.Denzinger S, Fritsche HM, Otto W, Blana A, Wieland WF, Burger M. Early versus deferred cystectomy for initial high-risk pT1G3 urothelial carcinoma of the bladder: do risk factors define feasibility of bladder-sparing approach?. Eur Urol. 2008 Jan;53(1):146-52.

104. Herr HW, Sogani PC. Does early cystectomy improve the survival of patients with high risk superficial bladder tumors? J Urol. 2001 Oct;166(4):1296-9.

105.Steinberg G, Bahnson R, Brosman S, Middleton R, Wajsman Z, Wehle M. Efficacy and safety of valrubicin for the treatment of Bacillus Calmette-Guerin refractory carcinoma in situ of the bladder. The Valrubicin Study Group. J Urol. 2000 Mar;163(3):761-7.

106.Dalbagni G, Russo P, Bochner B, Ben-Porat L, Sheinfeld J, Sogani $P$, et al. Phase II trial of intravesical gemcitabine in bacille Calmette-Guérin-refractory transitional cell carcinoma of the bladder. J Clin Oncol. 2006 Jun;24(18):2729-34.

107.Gallagher BL, Joudi FN, Maymí JL, O’Donnell MA. Impact of previous bacille Calmette- Guérin failure pattern on subsequent response to bacille Calmette-Guérin plus interferon intravesical therapy. Urology. 2008 Feb;71(2):297-301.

108.Herr HW, Milan TN, Dalbagni G. BCG-refractory vs. BCG-relapsing non-muscle- invasive bladder cancer: a prospective cohort outcomes study. Urol Oncol. 2015 Mar;33(3):108.e1-4.

109.Bui TT, Schellhammer PF. Additional bacillus Calmette-Guerin therapy for recurrent transitional cell carcinoma after an initial complete response. Urology. 1997 May;49(5):687-90.

110.Meyer J, Persad R, Gillatt DA. Use of bacille Calmette-Guérin in superficial bladder cancer. Postgrad Med J. 2002 Aug;78(922):449-54.

111. Herr HW, Donat SM. Outcome of patients with grossly node positive bladder cancer after pelvic lymph node dissection and radical cystectomy. J Urol. 2001 Jan;165(1):62-4.

112.Stein JP, Lieskovsky G, Cote R, Groshen S, Feng AC, Boyd S, et al. Radical cystectomy in the treatment of invasive bladder cancer: long-term results in 1,054 patients. J Clin Oncol. 2001 Feb;19(3):666-75.

113.Lightfoot AJ, Rosevear HM, O'Donnell MA. Recognition and treatment of BCG failure in bladder cancer. Sci World J. 2011 Mar;11:602-13.

114.Cookson MS, Herr HW, Zhang ZF, Soloway S, Sogani PC, Fair WR. The treated natural history of high-risk superficial bladder cancer: 15-year outcome. J Urol. 1997 Jul;158(1):62-7.
115.Sylvester RJ, Van Der Meijden AP, Witjes JA, Kurth K. Bacillus Calmette-Guerin versus chemotherapy for the intravesical treatment of patients with carcinoma in situ of the bladder: a meta-analysis of the published results of randomized clinical trials. J Urol. 2005 Jul;174(1):86-91.

116.Zehnder P, Studer UE, Skinner EC, Dorin RP, Cai J, Roth $B$, et al. Super extended versus extended pelvic lymph node dissection in patients undergoing radical cystectomy for bladder cancer: a comparative study. J Urol. 2011 Oct;186(4):1261-8.

117.Raj GV, Herr H, Serio AM, Donat SM, Bochner BH, Vickers AJ, et al. Treatment paradigm shift may improve survival of patients with high risk superficial bladder cancer. J Urol. 2007;177(4):1283-6.

118.Bianco Junior FJ, Justa D, Grignon DJ, Sakr WA, Pontes JE, Wood Junior DP. Management of clinical T1 bladder transitional cell carcinoma by radical cystectomy. Urol Oncol. 2004 Jul/Aug;22(4):290-4.

119.Chang SS, Cookson MS. Non-muscle-invasive bladder cancer: the role of radical cystectomy. Urology. 2005 Nov;66(\%):917-22.

120. Madersbacher S, Hochreiter W, Burkhard F, Thalmann GN, Danuser H, Markwalder R, et al. Radical cystectomy for bladder cancer today--a homogeneous series without neoadjuvant therapy. J Clin Oncol. 2003 Feb;21(4):690-6.

121.Stein JP. Indications for early cystectomy. Urology. 2003 Oct;62(4):591-5.

122. Montie JE. Against bladder sparing: surgery. J Urol. 1999 Aug;162(2):452-5;discussion:455-7.

124.Williams SB, Ray-Zack MD, Hudgins HK, Oldenburg J, Trinh QD, Nguyen PL, et al. Impact of centralizing care for genitourinary malignancies to high-volume providers: a systematic review. Eur Urol Oncol. 2019;2:265-73.

125.Scarberry K, Berger NG, Scarberry KB, Agrawal S, Francis JJ, Yih JM, et al. Improved surgical outcomes following radical cystectomy at high-volume centers influence overall survival. Urol Oncol. 2018 Apr;36(6):308.e11-.e17.

126.Santos F, Zakaria AS, Kassouf W, Tanguay S, Aprikian A. High hospital and surgeon volume and its impact on overall survival after radical cystectomy among patients with bladder cancer in Quebec. World J Urol. 2015 Sep;33(9):1323-30.

127.Kim SP, Shah ND, Karnes RJ, Weight CJ, Frank I, Moriarty JP, et al. The implications of hospital acquired adverse events on mortality, length of stay and costs for patients undergoing radical cystectomy for bladder cancer. J Urol. 2012 Jun;187(6):2011-7.

128.Williams SB, Huo J, Chamie K, Hu JC, Giordano $\mathrm{SH}$, Hoffman KE, et al. Underutilization of radical cystectomy among patients diagnosed with clinical stage T2 muscle-invasive bladder cancer. Eur Urol Focus. 2017 Apr;3(2-3):258-64

129.Zattoni F, Palumbo V, Giannarini G, Crestani A, Kungulli A, Novara G, et al. Perioperative outcomes and early survival in octogenarians who underwent radical cystectomy for bladder cancer. Urol Int. 2018;100(1):13-7. 
130.Pang KH, Groves R, Venugopal S, Noon AP, Catto JWF. Prospective implementation of enhanced recovery after surgery protocols to radical cystectomy. Eur Urol. 2018 Mar;73(3):363-71.

131.Chipollini J, Tang DH, Hussein K, Patel SY, Garcia-Getting RE, Pow-Sang JM, et al. Does implementing an enhanced recovery after surgery protocol increase hospital charges? Comparisons from a radical cystectomy program at a specialty cancer center. Urology. 2017 Jul;105:108-12.

132. Hautmann RE, Stein JP. Neobladder with prostatic capsule and seminal-sparing cystectomy for bladder cancer: a step in the wrong direction. Urol Clin North Am. 2005 May;32(2):177-85.

133. Kim HS, Jeong CW, Kwak C, Kim HH, Ku JH. Adjuvant chemotherapy for muscle- invasive bladder cancer: a systematic review and network meta-analysis of randomized clinical trials. Oncotarget. 2017;8(46):81204-14.

134.Steven K, Poulsen AL. Radical cystectomy and extended pelvic lymphadenectomy: survival of patients with lymph node metastasis above the bifurcation of the common iliac vessels treated with surgery only. J Urol. 2007 Oct;178(4 Pt 1):1218-23.

135.Leissner J, Ghoneim MA, Abol-Enein $\mathrm{H}$, Thuroff JW, Franzaring L, Fisch $\mathrm{M}$, et al. Extended radical lymphadenectomy in patients with urothelial bladder cancer: results of a prospective multicenter study. J Urol. 2004 Jan;171(1):139-44.

136.Gschwend JE, Heck MM, Lehmann J, Rubben H, Albers P, Wolff JM, et al. Extended versus limited lymph node dissection in bladder cancer patients undergoing radical cystectomy: survival results from a prospective, randomized trial. Eur Urol. 2019 Apr;75(4):604-11.

137.Cody JD, Nabi G, Dublin N, McClinton S, Neal $\mathrm{DE}$, Pickard $\mathrm{R}$, et al. Urinary diversion and bladder reconstruction/replacement using intestinal segments for intractable incontinence or following cystectomy. Cochrane Database Syst Rev. 2012;2012(2):CD003306.

138.Ali AS, Hayes MC, Birch B, Dudderidge T, Somani BK. Health related quality of life (HRQOL) after cystectomy: comparison between orthotopic neobladder and ileal conduit diversion. Eur J Surg Oncol. 2015 Mar;41(3):295-9.

139.Stein R, Hohenfellner M, Pahernik S, Roth S, Thüroff JW, Rübben $\mathrm{H}$. Urinary diversion-approaches and consequences. Dtsch Arztebl Int. 2012 Sep;109(38):617-22.

140.Zhou X, Ji H, Zhang H, Xiong T, Pan J, Chen Z. Treatment and outcomes of urethral recurrence after orthotopic neobladder replacement in patients with bladder cancer - practice in a single centre. J Int Med Res. 2018 Sep;46(9):3928-37.

141. Hassan JM, Cookson MS, Smith Junior JA, Chang SS. Urethral recurrence in patients following orthotopic urinary diversion. J Urol. 2004 Oct;172(4 Pt 1):1338-41.
142. Yamashita S, Hoshi S, Ohyama C, Satoh M, Soma F, Okada Y, et al. Urethral recurrence following neobladder in bladder cancer patients. Tohoku J Exp Med. 2003 Apr;199(4):197-203.

143.Levinson AK, Johnson DE, Wishnow KI. Indications for urethrectomy in an era of continent urinary diversion. J Urol. 1990 Jul;144(1):73-5.

144.Nahar B, Koru-Sengul T, Miao F, Prakash NS, Venkatramani V, Gauri A, et al. Comparison of readmission and short-term mortality rates between different types of urinary diversion in patients undergoing radical cystectomy. World J Urol. 2018;36(3):393-9.

145.Monn MF, Kaimakliotis HZ, Cary KC, Pedrosa JA, Flack CK, Koch MO, et al. Short- term morbidity and mortality of Indiana pouch, ileal conduit, and neobladder urinary diversion following radical cystectomy. Urol Oncol. 2014 Nov;32(8):1151-7.

146. Mao SY, Xiong DB, Huang TB, Cai KK, Xu L, Zheng $\mathrm{JH}$, et al. Urinary diversion by neobladder reconstruction after radical cystectomy in the elderly: outcomes and survival. Int J Clin Exp Med. 2016;9(12):23576-83.

147. Malavaud B, Vaessen C, Mouzin M, Rischmann P, Sarramon J, Schulman C. Complications for radical cystectomy. Impact of the American Society of Anesthesiologists score. Eur Urol. 2001 Jan;39(1):79-84.

148.Longo N, Imbimbo C, Fusco F, Ficarra V, Mangiapia F, Di Lorenzo G, et al. Complications and quality of life in elderly patients with several comorbidities undergoing cutaneous ureterostomy with single stoma or ileal conduit after radical cystectomy. BJU Int. 2016 Oct;118(4):521-6.

149.Deliveliotis C, Papatsoris A, Chrisofos M, Dellis A, Liakouras C, Skolarikos A. Urinary diversion in high-risk elderly patients: modified cutaneous ureterostomy or ileal conduit? Urology. 2005 Aug;66(2):299-304.

150.Hautmann RE, Volkmer BG, Schumacher MC, Gschwend JE, Studer UE. Long-term results of standard procedures in urology: the ileal neobladder. World J Urol. 2006 Aug;24(3):305-14.

151.Fontenot PA, Barnes BD, Parker WP, Wyre H, Lee EK, Holzbeierlein JM. Postoperative outcomes after radical cystectomy in patients with prior pelvic radiation. Urology. 2018 Jun;116:131-6.

152.Faba OR, Tyson MD, Artibani W, Bochner BH, Burkhard F, Gilbert SM, et al. Update of the ICUD-SIU International Consultation on Bladder Cancer 2018: urinary diversion. World J Urol. 2019 Jan;37(1):85-93.

153. Holzbeierlein JM, Lopez-Corona E, Bochner BH, Herr HW, Donat SM, Russo P, et al. Partial cystectomy: a contemporary review of the Memorial Sloan-Kettering Cancer Center experience and recommendations for patient selection. J Urol. 2004 Sep;172(3):878-81.

154.Chang SS, Cookson MS, Baumgartner RG, Wells $\mathrm{N}$, Smith Junior JA. Analysis of early complications after radical cystectomy: results of a collaborative care pathway. J Urol. 2002;167(5):2012-6. 
155.Fahmy N, Aprikian A, Tanguay S, Mahmud SM, Al-Otaibi M, Jeyaganth $S$, et al. Practice patterns and recurrence after partial cystectomy for bladder cancer. World J Urol. 2010 Aug;28(4):419-23.

156.Dandekar NP, Tongaonkar HB, Dalal AV, Kulkarni JN, Kamat MR. Partial cystectomy for invasive bladder cancer. J Surg Oncol. 1995 Sep;60(1):24-9.

157.Herr HW, Scher HI. Neoadjuvant chemotherapy and partial cystectomy for invasive bladder cancer. J Clin Oncol. 1994;12(5):975-80.

158.Sweeney P, Kursh ED, Resnick MI. Partial cystectomy. Urol Clin North Am. 1992 Nov;19(4):701-11.

159.Knoedler J], Boorjian SA, Kim SP, Weight CJ, Thapa $\mathrm{P}$, Tarrell RF, et al. Does partial cystectomy compromise oncologic outcomes for patients with bladder cancer compared to radical cystectomy? A matched case-control analysis. J Urol. 2012 Oct;188(4):1115-9.

160. Hussain MH, Glass TR, Forman J, Sakr W, Smith DC, Al-Sarraf $M$, et al. Combination cisplatin, 5-fluorouracil and radiation therapy for locally advanced unresectable or medically unfit bladder cancer cases: a Southwest Oncology Group Study. J Urol. 2001 Jan;165(1):56-60;discussion:60-1.

161.Shipley WU, Kaufman DS, Tester WJ, Pilepich MV, Sandler HM, Radiation Therapy Oncology Group. Overview of bladder cancer trials in the Radiation Therapy Oncology Group. Cancer. 2003 Apr;97(8 Suppl 1):2115-9.

162.Zietman A, Hunt D, Kaufman D, Uzzo R, Wu C, Buyyounouski MK, et al. Preliminary results of RTOG 0233: a phase II randomized trial for muscle-invading bladder cancer treated by transurethral resection and radiotherapy comparing two forms of concurrent induction chemotherapy. Int J Radiat Oncol Biol Phys. 2010 Nov;78(3 Suppl 1):S31-S2.

163.Mak RH, Hunt D, Shipley WU, Efstathiou JA, Tester WJ, Hagan MP, et al. Long-term outcomes in patients with muscle-invasive bladder cancer after selective bladder-preserving combined-modality therapy: a pooled analysis of Radiation Therapy Oncology Group protocols 8802, 8903, 9506, 9706, 9906, and 0233. J Clin Oncol. 2014 Dec;32(34):3801-9.

164.Rödel C, Grabenbauer GG, Kühn R, Papadopoulos T, Dunst J, Meyer M, et al. Combined-modality treatment and selective organ preservation in invasive bladder cancer: long-term results. J Clin Oncol. 2002 Jul;20(14):3061-71.

165.Turgeon GA, Souhami L. Trimodality therapy for bladder preservation in the elderly population with invasive bladder cancer. Front Oncol. 2014 Aug;4:206.

166.Smith ZL, Christodouleas JP, Keefe SM, Malkowicz $\mathrm{SB}$, Guzzo TJ. Bladder preservation in the treatment of muscle-invasive bladder cancer (MIBC): a review of the literature and a practical approach to therapy. BJU Int. 2013 Jul;112(1):13-25.

167.Giacalone NJ, Shipley WU, Clayman RH, Niemierko A, Drumm M, Heney NM, et al. Long-term outcomes after bladder-preserving tri-modality therapy for patients with muscle-invasive bladder cancer: an updated analysis of the Massachusetts general hospital experience. Eur Urol. 2017 Jun;71(6):952-60.
168.Vashistha V, Wang H, Mazzone A, Liss MA, Svatek RS, Schleicher M, et al. Radical cystectomy compared to combined modality treatment for muscle-invasive bladder cancer: a systematic review and meta-analysis. Int J Radiat Oncol Biol Phys. 2017 Apr;97(5):1002-20.

169.Arcangeli G, Arcangeli S, Strigari L. A systematic review and meta-analysis of clinical trials of bladder-sparing trimodality treatment for muscle-invasive bladder cancer (MIBC). Crit Rev Oncol Hematol. 2015 Apr;94(1):105-15.

170.Weiss C, Sauer R, Rödel C. Radiochemotherapeutic options for bladder cancer. Aktuelle Urol. 2008 Mar;39(2):123-9.

171. Weiss C, Wolze C, Engehausen DG, Ott OJ, Krause FS, Schrott KM, et al. Radiochemotherapy after transurethral resection for high-risk T1 bladder cancer: an alternative to intravesical therapy or early cystectomy? J Clin Oncol. 2006 May;24(15):2318-24.

172. Wo JY, Shipley WU, Dahl DM, Coen JJ, Heney NM, Kaufman DS, et al. The results of concurrent chemo-radiotherapy for recurrence after treatment with bacillus Calmette-Guérin for non-muscle-invasive bladder cancer: is immediate cystectomy always necessary?. BJU Int. 2009 Jul;104(2):179-83.

173.Baxter E, Dennis K, Kollmannsberger C, Black P, Attwell A, Morris WJ, et al. Radical trimodality therapy for patients with locally advanced bladder cancer: the British Columbia Cancer Agency experience. Urol Oncol. 2015;33(2):66.e13-9.

174.Goldsmith B, Baumann BC, He J, Tucker K, Bekelman J, Deville $C$, et al. Occult pelvic lymph node involvement in bladder cancer: implications for definitive radiation. Int J Radiat Oncol Biol Phys. 2014 Mar;88(3):603-10.

175.Ploussard G, Daneshmand S, Efstathiou JA, Herr HW, James ND, Rödel CM, et al. Critical analysis of bladder sparing with trimodal therapy in muscle-invasive bladder cancer: a systematic review. Eur Urol. 2014 Jul;66(1):120-37.

176. Mitin T, George A, Zietman AL, Heney NM, Kaufman DS, Uzzo RG, et al. Long-term outcomes among patients who achieve complete or near-complete responses after the induction phase of bladder-preserving combined-modality therapy for muscle-invasive bladder cancer: a pooled analysis of NRG Oncology/RTOG 9906 and 0233. . Int J Radiat Oncol Biol Phys. 2016 Jan;94(1):67-74.

177.Shipley WU, Kaufman DS, Zehr E, Heney NM, Lane SC, Thakral HK, et al. Selective bladder preservation by combined modality protocol treatment: long-term outcomes of 190 patients with invasive bladder cancer. Urology. 2002 Jul;60(1):62-7; discussion:67-8.

178. Lewis GD, Haque W, Verma V, Butler EB, Teh BS. The role of adjuvant radiation therapy in locally advanced bladder cancer. Bladder Cancer. 2018 Apr;4(2):205-13. 
179.Zaghloul MS, Christodouleas JP, Smith A, Abdallah A, William $\mathrm{H}$, Khaled $\mathrm{HM}$, et al. Adjuvant sandwich chemotherapy plus radiotherapy vs adjuvant chemotherapy alone for locally advanced bladder cancer after radical cystectomy: a randomized phase 2 trial. JAMA Surg. 2018 Jan;153(1):e174591.

180.Zaghloul M, Christodouleas JP, Hwang WT, Smith A, Abdalla A, William H, et al. Randomized phase III trial of adjuvant sequential chemotherapy plus radiotherapy versus adjuvant radiotherapy alone for locally advanced bladder cancer after radical cystectomy: Urothelial carcinoma subgroup analysis. J Clin Oncol. 2019;37(7 Suppl 1):S351.
181.Bryant CM, Dang LH, Stechmiller BK, Gilbert SM, Morris CG, Zlotecki RA. Treatment of small cell carcinoma of the bladder with chemotherapy and radiation after transurethral resection of a bladder tumor. Am J Clin Oncol. 2016 Feb;39(1):69-75.

182.Premo C, Apolo AB, Agarwal PK, Citrin DE. Trimodality therapy in bladder cancer: who, what, and when?. Urol Clin North Am. 2015 May;42(2):169-80. 